\title{
UM AROMA NO AR: A ECOLOGIA HISTÓRICA DAS PLANTAS ANTI-FANTASMA ENTRE OS GUAJÁ DA AMAZÔNIA
}

Loretta A. Cormier

"É o hálito de um fantasma"

(Tuzin 1975:556; resposta de um grupo de Arapesh Ilahita da Nova Guiné, quando instigados a decidir qual o pior odor imaginável)

Traçar a história de idéias entre povos indígenas não-letrados é um desafio, pois depende da habilidade de antropólogos e historiadores em traduzir essas experiências culturais para uma cronologia escrita, forma alheia a certos modos culturais de transmissão de idéias entre gerações. A disciplina da ecologia histórica concebe a paisagem como um texto indígena. Significados são inscritos e podem ser lidos na maneira como uma cultura altera seu ambiente natural ao longo do tempo e nas interpretações simbólicas que atribui a suas interações com plantas, animais e características ambientais. Convencionalmente, buscamos compreender a natureza humana e suas diversas expressões por meio da descoberta de uma presença - seja um artefato arqueológico, um gene biológico ou um meme cultural. Espero neste artigo demonstrar que uma ausência pode ser algo igualmente revelador.

Este trabalho descreve as aiyã, "plantas repelentes de fantasmas", dos Guajá da Amazônia oriental, em termos de seu significado simbólico, eficácia biológica e contexto ecológico-histórico. Entre os Guajá, fantasmas são encarnações da memória dos mortos. Em essência, fantasmas são desgosto e pesar, e o sofrimento é considerado um estado de espírito tão devastador que é preciso tomar medidas ativas para evitar esse mal. As plantas repelentes de fantasmas são identificadas por seu odor pungente, que neutraliza o mau cheiro dos fantasmas dos mortos, causador de doenças. Ironicamente, os ancestrais têm presença importante nessa cultura, mas eles só se manifestam por intermédio de esforços que assegurem sua 
ausência. Assim, a importância de negar a história é perpetuada por meio do uso de plantas medicinais anti-memória. Neste artigo, também situarei os Guajá no contexto amazônico mais amplo, comparando seus mecanismos de obliteração da memória histórica com o de outros grupos dotados de concepções similares.

Além disso, discutirei a hipótese de que essas plantas medicinais fornecem meios de ler a história do choque dos Guajá com os colonizadores europeus. Há indícios de que as plantas medicinais guajá sofreram transformações ao longo dos últimos 500 anos. Estimativas recentes sugerem que doenças do Velho Mundo podem ter dizimado populações inteiras (p.ex., Cook 1998; Denevan 1992; Dobyns 1983). Levando em conta, portanto, as proporções épicas que a morte e o sofrimento assumiram, sugiro que os repelentes de fantasmas foram elaborados e transformados como uma resposta indígena ao encontro histórico entre europeus e ameríndios, resposta essa inscrita, ainda hoje, no simbolismo vegetal guajá.

\section{Infecção pelos aiyã como síndrome culturalmente delimitada}

O contexto etnográfico

Os Guajá ${ }^{1}$ são um povo da Amazônia oriental, no limite ocidental do estado do Maranhão. Balée forneceu evidências ecológico-históricas de que os Guajá foram horticultores que reverteram a um estilo de vida coletor, provavelmente na seqüência da convulsão cultural que marcou o início da colonização européia (Balée 1992; 1994; 1999). A partir dos anos 1980, grupos de Guajá entraram em contato com populações não indígenas, e estão agora começando a reincorporar plantas domesticadas à sua dieta, a usar bens materiais ocidentais (como instrumentos de ferro) e a receber tratamento médico da Fundação Nacional do Índio (FUNAI) (ver Cormier 2003). Pode-se descrevê-los melhor por meio de um termo utilizado com freqüência cada vez maior: "sociedade pós-coletora" (p.ex., Barac 1999; Headland 2002; Trigger 1999). O termo reflete a inadequação de "coletor" ou "caçador-coletor" para os caçadores-coletores contemporâneos, que, em graus diversos, encontram-se social, política, econômica e/ou ecologicamente envolvidos com as sociedades ocidentais.

A despeito da recente integração de algumas tecnologias ocidentais a seu modo de vida, os Guajá continuam a depender, em grande medida, de produtos da floresta, utilizados como alimento, remédio, materiais de construção, e na confecção de vários outros objetos. Plantas empregadas em 
banhos curativos constituem, entre os Guajá, uma das categorias mais importantes de plantas medicinais. Seria mais exato descrever esses banhos como borrifamentos medicinais. Plantas aromáticas de odor forte são chamadas ka'akaçu'u. Folhas, talos, flores ou cascas são postos em infusão na água e essa água aromática é então borrifada sobre o corpo. Algumas vezes, braceletes de casca são colocados com o mesmo propósito em crianças ou animais de estimação. Na terminologia biomédica ocidental, esses borrifamentos aromáticos poderiam ser classificados como analgésicos ou antitérmicos.

Todavia, o efeito desejado dessas plantas medicinais conecta, também, os seus significados simbólicos e a relação dos Guajá com seres sobrenaturais. As plantas odoríferas repelem os aiyã fantasmas dos mortos, que se acredita causarem doenças ao penetrar o corpo com seu odor fétido, canibalizando então a alma da vítima. Os Guajá têm uma interpretação dualista do destino post mortem da alma, acreditando que ela se bifurca e perdura tanto sob uma forma malevolente terrena, o aiyã , quanto sob uma forma celestial sagrada, o hatikwatya.

Os hatikwatya também existem no interior do corpo dos viventes, mas se desligam do corpo no momento da morte e são transportados ao reino celestial dos ancestrais e divindades. Os aiyã passam a existir apenas com a morte. Esses aiyã vivem então em infelicidade e isolamento, e sua ânsia de se reconectar ao mundo dos vivos tem efeitos desastrosos. Quando penetram um corpo vivo, acredita-se que consomem o hatikwatya e são assim vistos, literalmente, como canibais. Os aiyã podem ser experimentados em múltiplos níveis sensórios. São visualizados como uma imagem do morto rondando as proximidades da aldeia; suas vozes são escutadas quando chamam os vivos; são percebidos tatilmente como um vento súbito, forte o bastante para derrubar uma pessoa; e, mais relevante para a discussão aqui, exalam um odor fétido similar ao de um corpo em decomposição. É sob este último modo sensorial que são mais letais.

\section{Simbolismo olfativo}

O odor é uma forma poderosa de comunicação, seja por sua presença física, seja por suas associações simbólicas. Classen (1992:133) argumentou que o simbolismo olfativo é utilizado transculturalmente para expressar temas de identidade e diferença, tanto no caso de sociedades altamente conscientes olfativamente, quanto no caso de sociedades "desodorizadas", como ela descreve a sociedade ocidental. Firth (1981:582) notou, certa 
vez, que Marx se refere à religião como "o aroma espiritual do mundo" (citando Marx 1927:607) e interpretou essa metáfora como significando que a religião é comparável a uma fragrância estética que oculta condições sociais deterioradas. Isso soa verdadeiro para os Guajá. Fantasmas são "outros" perigosos, com a capacidade potencial de provocar rupturas na ordem social. São detectados por seu odor e combatidos com fragrâncias estéticas neutralizadoras.

Na Amazônia, a crença de que odores estão associados a agentes causadores de doenças não é privativa dos Guajá. Werner (1987) descreveu o que chamou de teoria pneumática da doença, operativa entre os Warao e outros grupos amazônicos. Especificamente no caso dos Warao, inclui a crença de que a doença é causada pelo contágio de agentes odoríferos que invadem o corpo, afetando os órgãos e a alma da área penetrada. Os Warao consideram os odores como seres sobrenaturais independentes, que podem causar doenças quando penetram os corpos dos vivos. O remédio consiste na ingestão de uma planta perfumada que afasta o odor. Usos similares de odores neutralizantes foram documentados fora da Amazônia. Por exemplo, os Batek da Malásia esfregam seivas aromáticas na pele, para tratar doenças; e na Roma antiga, perfumes e guirlandas odoríferas constituíam maneiras de promover a boa saúde (Classen et alii 1994:40-41,147). A idéia geral de que cheiros ruins causam doença foi proposta [séc.II] pelo médico grego Galeno e, no século XI, pelo médico persa Avicena (Stoddart 1990:2).

Sheppard $(2000 ; 2004)$ comparou os atributos sensoriais das plantas usadas por dois grupos amazônicos lingüisticamente afastados, os Yora, de língua pano, e os Matsiguenga, de língua aruak, e descobriu que em ambos os casos o odor consistia na propriedade curativa mais freqüentemente descrita. Os Yora acreditam que seres yõshi malevolentes provocam doenças expondo as pessoas a seus odores fétidos, e os rituais de cura envolvem a inalação de plantas aromáticas cujos nomes são cantados pelos xamãs. Prática similar foi descrita pelos Shipibo-Conibo da Amazônia peruana, que tratam doenças com ervas odoríferas e cantos aromáticos (ver Classen et alii 1994:148). Para os Matsiguenga, assim como para os Guajá, doenças podem ser causadas por odores exalados por seres sobrenaturais pestilentos, que podem ser repelidos por meio de banhos com plantas aromáticas (Sheppard 2000; 2004). Embora os grupos amazônicos mencionados não sustentem crenças idênticas às dos Guajá, pode-se identificar um mesmo tema ideológico na atribuição, ao odor, de certa agência sobrenatural na causação de doenças. 


\title{
Eficácia das plantas anti-fantasma
}

\author{
Plantas medicinais dos Guajá
}

Durante meu trabalho de campo com os Guajá, coletei amostras botânicas de 276 espécies diferentes ${ }^{2}$. Alhures (Cormier 2002; 2003), argumentei que o conhecimento etnobotânico dos Guajá é consistente com seu modo de vida como povo coletor. O domínio de conhecimento etnobotânico mais importante é, de longe, o das plantas que servem de alimento para a caça. Várias plantas têm usos múltiplos, mas $84 \%$ daquelas identificadas por eles tinham pelo menos um uso: o de alimento para os animais caçados. Isso reflete a importância, para caçadores-coletores nômades, da compreensão do comportamento ecológico de suas presas, o que lhes permite localizá-las na floresta.

Da mesma maneira, a saliência dos repelentes de fantasmas no inventário das plantas medicinais guajá é uma indicação de sua relevância cultural. De modo geral, $14 \%(\mathrm{~N}=39)$ de todas as plantas identificadas pelos Guajá tinham pelo menos um uso medicinal. Plantas medicinais constituem entre eles a segunda mais importante categoria de conhecimento etnobotânico - a primeira é a das plantas relacionadas à subsistência (por serem comestíveis, seja para os humanos, seja para sua caça). Repelentes de fantasmas, por sua vez, constituem, por uma larga margem, a mais importante categoria de plantas medicinais, representando $67 \%$ do total $(\mathrm{N}=26)$. Considerando que aproximadamente dois terços de todas as plantas medicinais foram identificadas como utilizáveis para esse fim, temos uma clara medida da significância da infecção por fantasmas como uma categoria da etnonosologia guajá.

Repelentes de fantasmas diferem de outras plantas, não apenas por serem identificáveis pelo odor, mas também em sua natureza genérica. Tipicamente, e em termos amplos, os repelentes são caracterizados como plantas usadas para tratar dor e febre passíveis de provocar a morte. As descrições da maior parte dos demais remédios vegetais referiam-se a males bem mais restritos e específicos: cataplasmas para dores de dente, anticoagulantes para feridas, insenticidas tópicos contra carrapatos, medicamentos para edemas causados por mordidas de cobra ou para promover contrações uterinas pós-parto. Essa especificidade pode indicar uma longa história de experimentação, que estaria ausente no caso dos remédios mais genéricos para a infecção por fantamas. Além disso, a associação uniforme dos repelentes de fantasmas com doenças capazes de causar a morte é também uma diferença significativa. Essa categoria da aflição causadora 
de febre, dores e morte é consistente com os efeitos das doenças européias entre os povos indígenas amazônicos, que discutiremos mais adiante.

\section{Eficácia biomédica de borrifamentos medicinais}

A hipótese de que a proeminência das plantas anti-fantasma é um fenômeno pós-contato não deve ser entendida como sugestão de que elas remetem a uma etnocategoria sui generis de doença, originada com o contato. Antes, o argumento aqui é que a infecção por fantasmas constitui uma categoria indígena que experimentou uma expansão pós-contato. Taylor (1996) argumentou que, entre os povos amazônicos, a morte é em geral vista como um homicídio imputável à agência humana. Os fantasmas dos mortos incluemse nessa categoria, sendo ex-humanos com intenções malignas para com os vivos. Assim, a atual preponderância dos repelentes de fantasmas representa a expansão, em resposta às mortes maciças e à baixa populacional experimentadas pelos povos indígenas na seqüência do contato, de uma base preexistente de analgésicos e antitérmicos. Repelentes de fantasmas podem ser um combinado sincrético de remédios tradicionais, de ontologias indígenas da morte, e da crise produzida pelas doenças febris - doenças que, como bem se sabe, são a principal causa de morbidade e mortalidade nas populações do Novo Mundo desde o contato.

Isto posto, é também claro que doenças febris não se originaram com o contato. Doenças como arboviroses, toxoplasmose, tétano, triquinose e outras variedades de infecções febris existiam na Amazônia antes do contato (Wirsing 1985). Pode-se também notar que o efeito refrescante do banho talvez consista por si mesmo em uma resposta prática à febre. Ainda que esteja além do escopo deste artigo a apresentação de uma análise fitoquímica das plantas medicinais guajá, alguns exemplos sugerem que pelo menos algumas dessas plantas podem envolver a absorção cutânea de agentes febrífugos bioativos. Na África Ocidental, por exemplo, folhas de Anacardium occidentale - uma espécie adventícia — são usadas em banhos medicinais para reduzir a febre; os Huaraoni do Equador fazem aplicações tópicas de uma infusão de casca de Guatteria sp. com o mesmo objetivo, e os Wayãpi da Guiana Francesa empregam como antipirético uma decocção de folhas de Siparuna amazonica Mart. (Schultes e Raffauf 1990).

Os Guajá fazem uso de uma espécie não-domesticada de Anacardium, de uma Guatteria sp. e da mesma Siparuna amazonica Mart. em borrifos medicinais. O fato de haver utilização similar de uma espécie de Anacardium em outro continente (África) pesa a favor do potencial dessa planta como febrífugo. Quanto ao uso da Guatteria, embora seja observado em 
outro povo amazônico, os Huaraoni, estes estão distantes dos Guajá, tanto geográfica (Equador) quanto lingüisticamente. Já o emprego da Siparuna amazonica Mart. é observado entre os Wayãpi, que, estes sim, são lingüisticamente próximos aos Guajá, uma vez que ambas as línguas pertencem ao subgrupo VIII da família tupi-guarani (Jensen 1999; Rodrigues 1984/1985). Entretanto, antes do contato, os Wayãpi, Emerillon e Zo'é já se haviam separado do subgrupo VIII, vivendo em uma região ao norte do rio Amazonas e que hoje faz parte da Guiana Francesa, enquanto os demais membros desse subgrupo situavam-se em áreas da Amazônia oriental ao sul do Amazonas (Jensen 1999; Rodrigues 1984/1985). O uso de plantas similares para propósitos similares por grupos separados sugere que essas plantas possuem, efetivamente, propriedades antipiréticas. Além disso, como notaram Alexander e Parades (1998), remédios tópicos tenderam a ser desqualificados como magia, embora uma variedade de medicamentos aplicados topicamente sejam utilizados na biomedicina ocidental, como pomadas de nitroglicerina, adesivos de nicotina e analgésicos.

\section{Magia, placebos e eficácia}

É problemático caracterizar os borrifos medicinais como meramente mágicos ou simbólicos, ou como placebos; eles não só exibem elementos de todas essas categorias, como também podem ser considerados eficazes. Mesmo a utilização da terminologia biomédica para descrever suas funções como febrífugos ou analgésicos alopáticos é, em grande medida, irrelevante do ponto de vista dos Guajá, pois dor e febre são interpretados como sintomas fisiológicos de desordem nas relações sociais. Mais especificamente, são interpretados como sintomas de encontros com fantasmas ou memórias dos mortos, que eles acreditam ser prejudiciais a seu bem-estar.

Em trabalhos anteriores, eu mesma cometi o erro de caracterizar esses borrifamentos medicinais como magia ou placebo, porque seu modo de ação está inserido em crenças culturais sobre o canibalismo e a agência malévola dos fantasmas dos mortos (Cormier 2002; 2003). Hahn e Kleinman (1983:3) falam de curas e doenças "culturogênicas" ou "etnome-dicogênicas" ao se referirem aos efeitos terapêuticos ou patogênicos dos sistemas de crenças, observados em fenômenos como o efeito placebo, curas milagrosas e morte por feitiçaria. Descrever, porém, as plantas guajá como meros placebos mágicos é inadequado. Como Etkin (1988) argumentou, eficácia é algo que deve ser compreendido em termos dos efeitos desejados e nos quadros de expectativas culturais determinadas. A eficácia é uma construção tão cultural quanto a própria doença. Para os Guajá, 
borrifar sobre o corpo uma infusão odorífera proporciona uma barreira protetora contra a penetração do mau cheiro do aiyã no indivíduo. Tal intrusão resultaria na "devoração" (u'u) da alma da pessoa pelo aiyã. Se o efeito desejado da infusão é perfumar o corpo com uma substância aromática, então é claro que o resultado desejado é efetivamente obtido.

O borrifamento é importante não apenas devido ao odor da planta, mas também por tratar-se de uma infusão em água. Entre os Guajá, a chuva está relacionada ao espírito. É conceitualizada como uma manifestação das divindades na Terra. Um dos propósitos da chuva é penetrar a terra para purificar os cadáveres enterrados. O corpo é embelezado pela chuva e recriado como espírito. Trata-se de um processo gradual, mas depois de alguns anos, por meio da chuva divina, o cadáver é transformado e o aiyã associado a ele acaba por desvanecer-se.

Para evitar lembranças dos mortos, os Guajá dispõem de outros mecanismos, muitos dos quais similares aos utilizados por outros povos amazônicos. Apresentam uma forma extrema de amnésia genealógica: embora não mantenham tabus sobre os nomes dos mortos, é entretanto normativo esquecê-los. Depois de vários meses, os mortos não são mais referidos por seus nomes pessoais, mas identificados indiretamente por meio de uma relação social como "meu pai", "meu irmão", "meu afim". A maior parte dos Guajá tinha extrema dificuldade em lembrar o nome de um parente morto, ainda que a morte fosse recente de dois ou três anos. Uns poucos eram capazes de recuperar os nomes em questão, mas isso não era comum. Culturalmente, lembrar os mortos é apropriado apenas em contextos sagrados, como sonhos ou estados de transe (o ritual karawarc), quando os Guajá visitam a casa celeste dos ancestrais e divindades.

Os aiyã, enquanto corporificações da memória dos mortos, são prejudiciais quando invadem a vida cotidiana na forma de uma experiência de desgosto. Lembrar os mortos é uma experiência ritualizada, altamente controlada e perigosa, se enfrentada sem as proteções cerimoniais apropriadas. Taylor (1993) descreveu esse paradoxo no pensamento amazônico, que consiste na presença, entre muitos grupos, de memórias ativas para apagar a memória dos mortos, ao passo que os mortos desempenham um papel essencial na vida religiosa.

A necessidade dos Guajá de repelir a memória dos mortos não é diferente daquilo que Conklin (2001) descreveu em seu livro recente, Consuming Grief - o modo como o canibalismo funerário wari' consistia em uma maneira de lidar com o pesar causado pela morte e de evitar o que eles consideram o horror de permitir que o corpo de morto apodreça na sepultura. Essa autora também descreve a crença wari' de que o apego à lembrança dos 
mortos pode atrair seus fantasmas, e de que práticas tais como queimar as casas e posses de quem morre ajudam a obliterar sua memória (Conklin 2001:158-161). Práticas similares de destruição ou abandono dos pertences dos mortos foram descritas para outros povos amazônicos (p.ex., entre os Araweté por Viveiros de Castro 1992 e entre os Kayabi por Oakdale 2001).

Oakdale descreveu um processo de "esquecimento ritualizado" nos rituais jowasi kayabi, realizados para facilitar o apagamento da memória dos mortos. Ela emprega o conceito de "não-eventos" de Fogelson (1989:143), referente a eventos tão traumáticos que acabam desaparecendo da memória e consciência históricas. Tais eventos passam freqüentemente despercebidos na etnohistória. Todavia, para o entendimento da construção cultural de historicidades, é tão importante compreender o que é seletivamente lembrado, quanto o que é seletivamente esquecido. Pode-se presumir, dado o parentesco lingüístico entre os dois grupos, que a noção kayabi de 'angjang tenha relação com o aiyã dos Guajá. Os Kayabi acreditam que o 'angjang é uma substância física dos mortos que se fixa nos vivos e pode ser removida, submetendo os enlutados a um banho com folhas aromáticas (Oakdale 2001:387-389).

A concepção da memória dos mortos como uma substância conecta-se à crítica de Pollock (1996) da "antropologia do corpo", insatisfatória, diz ele, para compreender os conceitos de doença dos Kulina, uma vez que para estes últimos a doença está ligada a substâncias e processos por meio dos quais a pessoalidade é adquirida, expressa e transformada. Ele apresenta um argumento similar no capítulo que escreveu para o volume organizado por Becker e Valentine sobre a paternidade múltipla na Amazônia (Pollock 2002).

A paternidade múltipla consiste na crença, muito difundida na Amazônia, de que os fetos são criados por meio do acúmulo de sêmen. Entre os Guajá, acredita-se que as mulheres não desempenham outro papel na reprodução, além daquele de receptáculo para o sêmen masculino. Crêem que a quantidade de sêmen necessária para sustentar a vida é maior do que a que qualquer homem pode fornecer sozinho e, por isso, as mulheres têm múltiplos parceiros durante a gravidez, de modo a adquirir a quantidade suficiente para formar completamente uma criança. Assim, a crença é de que as crianças não têm um relacionamento biológico com as mulheres que as geraram, mas são biologicamente relacionadas a todos os parceiros sexuais de suas mães.

Voltando a Pollock, seu argumento é de que a noção de paternidade compartilhada deve ser compreendida nos quadros de uma concepção mais ampla do compartilhamento de substância. Acredito que outra articulação pode ser encontrada na descrição de Viveiros de Castro (2001) para 
as concepções de afinidade, consangüinidade, perspectivismo e consangüinização dos afins - consangüinização que entre os Wari' (Conklin 2001) e os Huoarani (Rival 2002) é vista como transferência real de substância entre indivíduos vivendo em estreita proximidade (ver também Taylor 1998). Fiorini (2003) tenta identificar no canibalismo um tropo subjacente na Amazônia, e que abarcaria os trabalhos de Viveiros de Castro, Overing e Conklin sob a rubrica de uma escatologia da memória. Para cristalizar esses enquadramentos teóricos, o argumento central é o de que o parentesco na Amazônia não diz respeito à descendência a partir de um ancestral histórico dado e que tem muito mais a ver com sangue, suor e lágrimas - que se acredita unirem fisicamente os vivos uns aos outros.

\section{Conexão biológica entre olfato, emoção e memória autobiográfica}

A relação entre emoção e cultura é um campo de investigação antropológica em expansão. Diversos pesquisadores têm criticado a suposição de que estados emocionais são universais, argumentando que, ao menos em parte, eles são culturalmente construídos e mediados (p.ex., Abu-Lughod 1986; Lutz 1986; Lutz e White 1986). Existe também algum debate quanto ao grau em que as categorias semânticas para a experiência emocional variam (p.ex., Wierzbicka 1986; 1988) ou se mantêm consistentes (p.ex., Moore et alii 1999) de uma cultura para outra. Outros autores defenderam a idéia de que estados emocionais são uma área particularmente relevante para a investigação antropológica porque transcendem dicotomias tradicionais como hereditariedade/ambiente [nature/nurture], mente/corpo, sentimento/pensamento (p.ex., Izard 1983; Leavitt 1996; Lutz 1986). Dispensou-se também atenção a mudanças históricas no discurso e prática emocionais (Reddy 1997), ao papel da emoção na moldagem da consciência histórica (Harkin 2003) e à emoção como agência social (Lyon 1995).

Uma área adicional de investigação acerca da variação transcultural dos estados emocionais - relevante para os objetivos deste ensaio - envolve os trabalhos em sinestesia, a relação entre cores e emoções (D'Andrade e Egan 1974; Johnson et alii 1988). Uma observação interessante é que a variabilidade cultural nas associações de cores a estados emocionais é bem maior quando se trata de matizes, do que quando estão em jogo luminosidade e saturação. Simplificando um pouco o argumento, encontrouse considerável paralelismo, de uma cultura para outra, na associação entre intensidade cromática e intensidade emocional, mas os significados de um matiz variam mais amplamente. Ainda que os pesquisadores não tenham conseguido fornecer uma explicação para esse fato, ele sugere que, no caso 
da associação entre emoções e cores, estamos diante da presença simultânea de uma resposta inata e de uma resposta culturalmente mediada.

Respostas a odores, da mesma maneira, podem ter tanto uma base biológica quanto uma valência culturalmente mediada para interpretação. Uma linha de investigação experimental na psicologia, envolvendo memória, emoção e experiências olfativas, refere-se à investigação do chamado "fenômeno Proust". O termo deriva de uma passagem de No caminho de Swann, um dos sete livros de Marcel Proust reunidos sob o título de Em busca do tempo perdido. Proust descreve um súbito e intenso fluxo de lembranças da infância, desencadeado pelo cheiro de uma madalena molhada no chá de tília. Em psicologia, o "fenômeno Proust" sugere, em primeiro lugar, que odores podem evocar memórias detalhadas e vívidas, e, em segundo lugar, que essas memórias evocadas por odores são mais carregadas emocionalmente do que memórias evocadas por outros estímulos sensoriais (Herz et alii 2004; Chu e Downes 2000b). Memórias olfativas podem servir como marcadores do que os psicólogos classificam como "memórias autobiográficas" da experiência pessoal, e há evidências de que, entre estas, tendem a predominar as memórias de longo prazo (Chu e Downes 2000a). Técnicas de visualização neuronal demonstram que a rememoração evocada por odores estimula uma área específica do cérebro - a amígdala que se conecta diretamente ao sistema olfativo e está ligada à memória emocional (Herz et alii 2004; Royet et alii 2000; Zald e Pardo 1997).

À luz de tudo isso, o uso de plantas aromáticas para mascarar odores que fazem recordar os mortos pode não ser diferente do ato de queimar seus pertences, uma vez que ambos consistem em meios para evitar o desencadeamento de lembranças. Todavia, para fazer eu mesma o papel de advogado do diabo, um problema com essa interpretação é que os aiyã são seres sobrenaturais, e não manifestações externas reais que poderiam, biologicamente, desencadear o chamado fenômeno proustiano. Em outras palavras, não existe aqui um objeto físico malcheiroso, e sim a crença de que os fantasmas são fétidos. Embora eu não possa explicar plenamente por que os Guajá acreditam serem capazes de sentir o cheiro de fantasmas ou, talvez, por que de fato o sintam - posso afirmar que essas experiências não são privativas deles. Classen (1992) apontou que mesmo odores que dependem efetivamente de um desencadeador externo podem ser distorcidos em função de crenças culturais. Ela observa que se, por um lado, a dieta e a genética desempenham um papel na produção de diferenças nos odores corporais humanos de uma cultura para outra, odores são, por outro lado, muitas vezes exagerados e percebidos como um modo de diferenciar o outro ${ }^{3}$. Especificamente, afirma ela, "o mau cheiro atribuído ao 
outro é menos uma resposta a uma percepção real do odor do outro do que uma potente metáfora para a degeneração cultural que se teme que este outro, simplesmente por ser 'outro', venha a causar na ordem estabelecida" (Classen 1992:135). Ela fornece numerosos exemplos de distinções sociais traçadas com base em raça, gênero, religião e cultura, nas quais um grupo, essencialmente, afirma que o outro "fede".

Na Amazônia, os Suyá e os Kulina distribuem odores em um contínuo do tipo natureza/cultura, associando odores desagradáveis mais estreitamente à natureza (Pollock 1996:325; Seeger 1981:107-108; Classen 1990:729-730). De maneira algo similar, os Tehuelche se referem àqueles que violam as normas culturais que proíbem a divulgação de informação religiosa a forasteiros como "gambás", empregando como metáfora aqueles seres que revelam sua presença por seu odor repulsivo (Siffredi 2002:301). A metáfora não é tão diferente da expressão americana "I smell a rat" ["sinto cheiro de um rato"], usada com referência à presença de um traiçoeiro, "rat fink" [lit. "rato delator", dedo-duro]. Falando de algo mais próximo à experiência dos Guajá, Classen (1992) também argumenta que odores exagerados podem ser atribuídos a seres sobrenaturais, como na crença cristã tradicional de que o diabo e os fantasmas cheiram a enxofre. Eu acrescentaria que, visitando sites que tratam do tema da paranormalidade, depareime com a mesma atribuição de um odor sulfúrico a transformações mais recentes de criaturas diabólicas, como nas descrições de encontros com alienígenas espaciais ou com o "Pé-Grande", o homem-macaco da costa noroeste do Pacífico.

\section{A ecologia histórica das plantas anti-fantasma}

\section{Zoonoses}

O impacto devastador das doenças européias nas populações do Novo Mundo exige que se compreenda tanto a introdução dos agentes patogênicos em si mesmos, quanto as diferentes condições ecológicas que facilitaram a proliferação das moléstias. Como é bem sabido, muitas das doenças que afetaram essas populações eram, presumivelmente, zoonoses, como varíola, catapora, sarampo, e alguns tipos de gripe, particularmente aqueles transmitidos por aves e suínos (p. ex., Crosby 1994:85-86; Hackett 1994:91). A domesticação de animais no Velho Mundo ensejou a transferência de doenças animais para a população humana, e assentamentos densamente povoados permitiram a difusão contínua dessas doenças, 
transmitidas de um hospedeiro humano para outro. Ao longo do tempo, a co-evolução de agentes patogênicos e populações humanas criou uma sintomatologia menos virulenta no Velho Continente. Todavia, algumas novas doenças emergentes - como a epidemia de gripe que ocorreu entre 1556 e 1560 - devastaram populações tanto do Novo como do Velho Mundo (McNeil 1989:218). Exemplos mais recentes são a AIDS e o vírus do Nilo Ocidental. Assim, quando falamos em ecologia histórica das doenças, deve-se entender que não estamos nos referindo apenas a um artefato do encontro entre o Velho Mundo e o Novo Mundo, mas de um processo contínuo, ainda em curso na moderna globalização.

Em termos de padrões de assentamento, algumas populações andinas e mesoamericanas pré-colombianas ( $\mathrm{e}$, possivelmente, também cacicados amazônicos) eram densas o suficiente para permitir a infecção zoonótica humana em cadeia. E, de fato, quando as doenças zoonóticas foram introduzidas, espalharam-se rapidamente por essas populações, com efeitos devastadores (p.ex., Alden e Miller 1987; McNeil 1989:215-218). Todavia, não existiam entre os grupos pré-colombianos os tipos de domesticação animal que alimentaram a difusão de doenças zoonóticas observada no Velho Mundo. A domesticação de animais na América do Sul limitava-se às terras altas andinas, incidindo sobre três espécies: a alpaca, o lhama, e o porquinho-da-índia ${ }^{4}$. Segundo McNeil (1989:210-211), o lhama e a alpaca formavam populações dispersas, e não rebanhos suficientemente grandes para sustentar cadeias infecciosas. O porquinho-da-índia vivia dentro das casas e há indícios de que servia tanto como hospedeiro, quanto como reservatório de pelo menos um parasito que afeta humanos, o da doença de Chagas (Coimbra 1988:89-90). Assim, há entre o Velho Mundo e a América do Sul ao menos uma diferença significativa quanto ao grau de domesticação de animais, sendo que entre os povos amazônicos havia total ausência de tal domesticação.

O porquê dessas diferenças é uma questão lateral interessante. A idéia de que a Amazônia seria desprovida de animais adequados à domesticação constitui possivelmente um mito popular. Existem várias espécies que poderiam ter sido domesticadas, como a cotia, a paca, a anta, pecaris e diversos galináceos (Hunn 1982) e, no entanto, embora tenham domesticado plantas, os povos amazônicos não o fizeram com os animais.

\section{Malária}

A segunda principal causa de doenças febris é a malária, causada por um plasmódio transmitido pelo mosquito vetor Anopheles. A ecologia da malária tem um quadro mais complicado que o das zoonoses, envolvendo uma longa 
história de debates acerca da existência pré-colombiana da doença nas Américas. Wood (1975:93-94) revisou parte das evidências de ambos os lados do debate. Um dos argumentos-chave em favor da existência pré-colombiana da malária é sua presença em populações asiáticas pré-históricas, sugerindo que a doença poderia ter penetrado o Novo Mundo com a migração dos primeiros indígenas americanos. Wood assinala que indícios de representações de mosquitos na cerâmica do Novo México e traduções de várias palavras maya, sugestivas de infecção por malária, foram usadas para defender essa hipótese.

Pode-se buscar apoio adicional para esse ponto de vista no argumento de que algumas formas de malária seriam possivelmente zoonoses indígenas. Daviews et alii (1991:655) sugeriram que, por existir um estreito parentesco genético entre o Plasmodium brasilianum, que infecta os macacos americanos, e o Plasmodium malariae, que infecta humanos, este último poderia ser uma versão zoonótica do primeiro, com os macacos servindo de hospedeiros-reservatório para a doença humana. Garnham e Kuttler (1980) também identificaram um parasita malárico (Plasmodium odocoilei) no veado-de-virgínia (Odocoileus virginianus), no Texas, e, baseados na fisiologia comparativa dos plasmódios nos ungulados do Velho Mundo, levantam a hipótese de que cervídeos teriam trazido o plasmódio para o Novo Mundo no Plioceno. Embora sua pesquisa não responda diretamente à questão da presença pré-colombiana da malária em populações humanas, sua análise tanto dá apoio à hipótese da introdução da doença pela rota do estreito de Behring, quanto levanta a possibilidade de uma transferência pré-colombiana entre espécies, envolvendo as populações humanas.

Wood (1975:93-94) também descreve dois argumentos-chave a favor de uma origem mais recente - pós-contato — da malária. O primeiro é a ampla difusão do plasmódio nos mamíferos da África e Ásia (ao contrário do que ocorre nas Américas); o segundo, a ausência, entre os ameríndios, dos traços genéticos (como o traço falciforme) associados à resistência à doença $^{5}$ (ver também McNeil 1989:219-221; Wirsing 1985). Ambas as linhas de argumentação sugerem que a malária tem, no Velho Mundo, uma história evolutiva mais longa. McNeil sustentou que a diversidade das malárias que afligem os primatas do Velho Mundo, em conjunto com o estreito parentesco genético entre os tipos de malária que afligem humanos e macacos nas Américas, sugere que a doença destes tenha sido antroponoticamente*adquirida de seres humanos.

A suposição subjacente à hipótese da introdução recente da malária é a de que ela foi trazida ao Novo Mundo por meio do tráfico de escravos. A título de analogia, há indícios mais claros de que a febre amarela - 
outra doença transmitida por mosquitos - foi introduzida dessa maneira. Existe amplo acordo quanto ao fato de que tanto o mosquito vetor quanto o organismo viral foram trazidos para as Américas com os escravos, sendo então os ameríndios infectados com a doença e as populações de primatas afetadas por transmissão antroponótica (p. ex., Dobyns 1993; Fenner 1980; Wirsing 1985). Além disso, a infecção antroponótica por malária em macacos americanos foi demonstrada experimentalmente.

É provavelmente um equívoco ver a transmissão de humanos para macacos e a de macacos para humanos como mutuamente excludentes; mais provavelmente, trata-se de um mecanismo de feedback positivo entre infecções zoonóticas e antroponóticas simultâneas, por meio do qual macacos servem de reservatório para malárias humanas e humanos de reservatório para malárias de macacos. Tal cenário é bastante verossímil no caso dos Guajá, que mantêm grande quantidade de macacos como animais de estimação (ver Cormier 2003), proporcionando oportunidades para a transmissão interespécies - de populações humanas para macacos e vice-versa.

\section{Ecologia da doença}

Tentar determinar se o plasmódio da malária existia no Novo Mundo em tempos pré-colombianos poderia nos levar a, literalmente, perder o barco. A questão-chave não é saber se a malária foi ou não introduzida pelos navios carregados de escravos africanos, e sim compreender as condições ecológicas históricas que causaram as epidemias maláricas, fossem elas, ou não, doenças "em solo virgem" [i.e., população local exposta a uma doença para a qual não tem imunidade adquirida]. O trabalho pioneiro de Livingstone (1958), sobre a relação entre instrumentos de metal, agricultura de coivara, proliferação da malária e a adaptação genética representada pelo traço falciforme, não era uma pesquisa sobre a introdução de um novo organismo patogênico; buscava, antes, compreender as condições culturais e ecológicas que promoveram a propagação de uma doença já existente.

Trabalhos recentes em ecologia histórica amazônica podem fornecer um paralelo à disseminação da malária na África Ocidental, descrita por Livingstone. A pesquisa histórica e arqueológica tem demonstrado que a Amazônia pré-colombiana era muito mais populosa e desenvolvida do que antes se suspeitava (p. ex., Balée e Erikson, no prelo). Denevan (1992) descreveu o que se pode chamar um retrocesso ecológico entre 1500 e 1750.

*[N.T.]. Antroponótico = 'relativo a antroponose'; o termo sugere significação correspondenteinversa à de zoonose/zoonótico: transmissão de doença do homem para outros animais. 
Ele sugere que, na Amazônia (e no Novo Mundo, de modo geral), antes do contato, a paisagem era bem mais desenvolvida do que em 1750, quando registros históricos mais completos começam a se constituir. A paisagem era, em suma, mais selvagem em 1750 do que em 1500. A devastação dos povos indígenas pelas novas doenças levou ao desaparecimento da maior parte dos agentes ecológicos humanos no Novo Mundo. Conseqüentemente, entre 1500 e 1750, tem lugar um 'reflorestamento' do espaço negativo, do espaço antes ocupado por humanos.

No artigo original de Livingstone, o autor citava uma fonte que notara o fato de que, em zonas da África Central que reverteram às características de selva, vetores da malária viam-se significativamente reduzidos:

Achamos que seria interessante saber qual seria o estado de coisas quando as árvores-da-borracha estivessem crescidas e as ravinas e pântanos tivessem recuperado a vegetação. Fizemos um levantamento na fazenda de Mount Barklay, onde o mato ou o capim alto cresceram, nas margens dos córregos. Depois de uma longa busca, encontramos apenas duas ou três larvas, $A$. mauritianium e A. obscurus. Em um poço próximo a uma aldeia, havia $A$. costalis em quantidade (Barber, Rice e Brown 1933:629 apud Livingstone 1958) [notar que, segundo Livingstone, A. costalis = A. gambiae $]$.

Além disso, a sugestão era a de que tal "re-matamento" ["rejungalization"] poderia constituir uma forma de intervenção sensata para combater a malária. O reflorestamento de zonas de agricultura de coivara poderia alterar as condições ecológicas que permitiram a proliferação dos vetores anofelinos da malária.

Assim, existissem ou não vetores de malária nas florestas tropicais americanas na era pré-colombiana, podemos presumir que, mesmo que a doença fosse um problema de saúde importante em 1500, o reflorestamento amazônico subseqüente à baixa populacional teria alterado significativamente o ambiente ecológico que permitira sua proliferação. Tenha o plasmódio sido introduzido por escravos africanos, ou ressurgido devido a novas adaptações ecológicas, o resultado seria o mesmo: uma nova geração de povos amazônicos exposta a uma ameaça desconhecida de seus ascendentes imediatos. Ironicamente, se Denevan está correto, e independentemente de plasmódios da malária nativos terem ou não existido no mundo pré-colombiano, este repetiu as condições ecológicas nas quais o plasmódio africano proliferou. 


\section{Discussão}

Apresentei múltiplas perspectivas sobre as plantas anti-fantasma dos Guajá; perspectivas que, à primeira vista, podem parecer contraditórias: a associação simbólica de plantas aromáticas com repelentes estruturais de odores causadores de doenças, associados à putrefação da morte; a relação entre estímulos olfativos e memória autobiográfica; evidências transculturais da eficácia anti-pirética de banhos medicinais; e o argumento ecológico-histórico quanto à elaboração de remédios febrífugos em resposta a doenças do Velho Mundo. Acredito, todavia, que essas explicações, longe de opostas, são complementares e que, quando integradas, oferecem uma interpretação holística da natureza multidimensional da etnomedicina guajá. Fenômenos culturais não podem ser reduzidos a necessidade material, determinismo genético, condições ecológicas, circunstância histórica, crença tradicional ou explanação simbólica. Antes, consistem no produto de todos esses fatores operando simultaneamente, constituindo-se e influenciando-se uns aos outros.

Argumentei que as plantas usadas pelos Guajá para afastar fantasmas poderiam ser indevidamente caracterizadas como placebos ou magia, em termos das construções biomédicas ocidentais da eficácia alopática. Caracterizá-las como febrífugos ou analgésicos seria equivocado, pois febre e dor são sintomas atribuídos à infecção por fantasmas, um mal social que pode ser combatido com banhos medicinais. Se o efeito desejado do repelente de fantasma é alterar o cheiro do corpo, então as plantas são, de fato, eficazes.

De modo um tanto mais sutil, sugeri um elo entre o poder dos estímulos olfativos em evocar memórias do passado e o uso de plantas aromáticas para intervir no chamado fenômeno proustiano. O uso de plantas aromáticas pode envolver mais um simbolismo do tipo da doutrina das assinaturas*, como se observa quando plantas leitosas são usadas como remédios relacionados à lactação (p. ex., Etkin 1988). Mas o olfato, seja ele compreendido como primariamente biológico, seja como primariamente simbólico, parece um rico campo de experiência para maior exploração das conexões entre memória, sofrimento, pessoalidade, etnomedicina e cosmologia - podendo constituir, conforme sugeriu Shepard (2004), um componente da "ecologia sensorial" como campo de investigação.

A ecologia histórica também é relevante para a compreensão do inventário de plantas medicinais dos Guajá. Populações ameríndias foram devastadas por

*[N.T.] A "doutrina das assinaturas", proposta por Paracelso (e desenvolvida por Giambattista Porta em sua Fitognomônica, de 1588), propõe que certas marcas ou características exteriores das plantas indicariam suas propriedades e aplicações medicinais. 
doenças para as quais não tinham imunidade natural. O contato europeu levou à introdução de vírus zoonóticos e infecções transmitidas por insetos, causadoras de febre, dor e morte - a mesma tríade que os repelentes de fantasmas são, supostamente, capazes de curar. Além da coerência entre a sintomatologia das afecções tratadas por essas plantas medicinais e a intervenção curativa nas doenças introduzidas, há dois fatores adicionais em apoio a esse argumento: a predominância dos repelentes de fantasmas no inventário medicinal e o caráter genérico da cura. Dois terços das plantas medicinais usadas pelos Guajá eram "repelentes de fantasmas" que envolviam a produção de uma infusão de folhas, talos, raízes ou cascas de plantas aromáticas na água e o borrifamento dessa solução sobre o corpo. O evidente predomínio desse tipo de tratamento reforça a hipótese de uma inflexão histórica em sua importância. Além disso, argumentei que o caráter genérico da descrição guajá para essa categoria nosológica sugere uma profundidade temporal menor e uma história mais recente de intervenção sobre esse problema. A maior parte das outras plantas está associada a intervenções curativas contra males descritos de modo bem mais específico.

Em conclusão, considerando o contexto amazônico mais amplo, podemos reunir certo número de motivos ideológicos: o sofrimento é monstruoso, perigoso, e nocivo; é uma fome que pode consumir a alma; pode pegar a pessoa desprevenida, como aroma trazido pelo vento; e, porque ele está sempre à espreita, é preciso proteger-se, lembrando-se de esquecer ${ }^{6}$. Os Guajá são um caso ilustrativo desse motivo amazônico. Embora não falem muito do sofrimento propriamente dito, dispõem de meios potentes de comunicar entre si o poder deste último, por intermédio do uso de plantas aromáticas. Além do mais, não é apenas seu sistema de crenças que eles inscrevem e perpetuam através da interação com o ambiente: talvez possamos ler, também, a própria história européia nas características das plantas medicinais guajá, que sugerem que o sofrimento tornou-se o mal mais saliente a exigir remédio. A idéia da paisagem como texto pode parecer exótica para sensibilidades ocidentais, mas deveríamos lembrar que polpa de árvore prensada e tinturas vegetais são o papel e a tinta que usamos para inscrever nossa própria história.

Recebido em 20 de janeiro de 2005

Aprovado em 10 de março de 2005

Tradução de Marcela Coelho de Souza

Loretta A. Cormier é professsora de antropologia na University of Alabama em Birmingham. E-mail: <lcormier@uab.edu>. 


\section{Notas}

${ }^{1}$ Neste trabalho, como em outros, emprego o termo "Guajá". Os Guajá chamam a si mesmos "Awá", um termo tupi-guarani muito comum que significa "gente". Eles também se referem a si próprios por meio do vocábulo português "Guajá", e não o consideram pejorativo. Historicamente, "Guajá" é uma derivação de um termo brasileiro mais antigo, "gwazá", possivelmente um derivado de wazaizara ("dono do ornamento de penas"), usado pelos Guajarara e Tembém para os Guajá (Nimuendajú 1948:135).

${ }^{2}$ O leitor pode consultar Balée 1994, que fornece um inventário das plantas conhecidas pelos Guajá mais exaustivo do que o apresentado aqui. As espécies foram identificadas por intermédio dos herbários do Museu Goeldi em Belém e da Universidade de Tulane, Nova Orleans.

${ }^{3}$ Populações humanas exibem, efetivamente, variabilidade na estrutura e tamanho do órgão axilar e glândulas apócrinas associadas (Stoddart 1990:61), que influenciam odores corporais. Todavia, a argumentação de Classen procura ressaltar o fato de que potentes significados simbólicos são ligados à percepção do odor do "outro".

${ }^{4}$ Embora o cão não tenha sido domesticado no Novo Mundo (Savolainen et alii 2002), deve-se notar que esse animal doméstico estava presente em alguns grupos antes de seu contato (Schwartz 1997:34-36).

${ }^{5}$ Wood (1975) também forneceu evidências experimentais de que o mosquito Anopheles demonstra uma significativa preferência estatística por sangue do tipo O sobre os tipos A e B.

${ }^{6}$ Tomo essa frase do artigo de Taylor (1993), "Remembering to forget: identity, mourning, and memory among the Jivaro". 


\section{Referências bibliográficas}

ABU-LUGHOD, Lila. 1986. Veiled sentiments: honor and poetry in a bedouin society. Berkeley: University of California Press.

ALDEN, Dauril e MILLER, Joseph C. 1987. "Out of Africa: the slave trade and the transmission of smallpox to Brazil, 1560-1831". Journal of Interdisciplinary History, 18: 195-224.

ALEXANDER, Michelle M. e PARADES, J. Anthony. 1998. "Possible efficacy of a creek folk medicine through skin absorption: an object lession in ethnopharmacology". Current Anthropology, 39: 545549.

BALÉE, William. 1999. "Mode of production and ethnobotanical vocabulary: a controlled comparison of Guajá and Ka'apor (Eastern Amazonian Brazil)". In: Ted L. Gragson e Ben G. Blount (eds.), Ethnoecology: knowledge, resources, and rights. Athens: University of Georgia Press. pp. 24-40.

- 1994. Footprints of the forest: Ka'apor ethnobotany - the historical ecology of plant utilization by an amazonian people. New York: Columbia University Press.

. 1992. "People of the fallow: a historical ecology of foraging in lowland South America". In: Kent H. Redford e Christine Padoch (eds.), Conservation of neotropical forests: building on traditional re- source use. New York: Columbia University Press. pp. 35-57. . e ERICKSON, Clark (eds.). no prelo. Time and complexity in historical ecology: studies from the neotropical lowlands. New York: Columbia University Press.

BARAC, Victor. 1999. "From primitive to pop: foraging and post-foraging hunter-gatherer music". In: Richard B. Lee e Richard Daly (eds.), Cambridge encyclopedia of hunters and gatherers. Cambridge: Cambridge University Press. pp. 434-440.

BARBER, M.A. et alii. 1932. "Malaria studies on the firestone rubber plantation in Libera, West Africa". American Journal of Hygiene, 15: 601-633.

BATTAGLIA, Debbora. 1992. "The body in the gift: memory and forgetting in sabarl mortuary exchange". American Ethnologist, 19:3-18. 1993. "At play in the fields (and borders) of the imaginary: melanesian transformations of forgetting". Cultural Anthropology, 8: 430-442.

BROWN, Peter J. 1997. "Culture and the global resurgence of malaria". In: Marcia C. Inhorn e Peter J. Brown (eds.), The anthropology of infectious disease: international health perspectives. The Netherlands: Gordon and Breach Publishers. pp. 119-141. 
BURNS, Alistair. 2000. "Might olfactory dysfunction be a marker of early Alzheimer's disease?" Lancet, 355: 84-85.

CHU, Simon e DOWNES, John J. 2000a. "Long live Proust: the odour-cued autobiographical memory bump". Cognition, 75:B41-B45.

. 2000b. "Odour-evoked autobiographical memories: psychological investigations of proustian phenomena". Chemical Senses, 25:111-116.

CLASSEN, Constance, HOWES, David, e SYNNOTT, Anthony. 1994. Aroma: a cultural history of smell. London/New York: Routledge.

CLASSEN, Constance. 1992. "The odor of the other: olfactory symbolism and cultural categories". Ethos, 20: 133-166.

. 1990. "Sweet colors and fragrant songs: sensory models of the Andes and Amazonia". American Ethnologist, 17:722-735.

COIMBRA, Carlos E. A. 1988. "Human settlements, demographic pattern, and epidemology in lowland Amazonia: the case of Chagas's disease. American Anthropologist, 90: 82-97.

CONKLIN, Beth A. 2001. Consuming grief: compassionate cannibalism in an amazonian society. Austin: University of Texas Press.

CONTACOS, Peter G. e COLLINS, William E. 1968. "Falciparum malaria transmission from monkey to man by mosquito bite". Science, 161:56.

COOK, Noble D. 1998. Born to die: disease and New World conquest,
1492-1650 (new approaches to the Americas). Cambridge: Cambridge University Press.

CORMIER. 2003. Kinship with monkeys: The Guajá foragers of eastern Amazonia. New York: Columbia University Press.

. 2002. "Monkey ethnobotany: preserving biocultural diversity in Amazonia". In: John R. Stepp, Felice S. Wyndam e Rebecca Zarger (eds.), Ethnobiology and biocultural diversity: proceedings of the seventh international congress of ethnobiology. Athens: University of Georgia Press. pp. 313-325.

CROSBY, Alfred W. 1994. Germs, seeds, and animals: studies in ecological history. Armonk/New York/London: M.E. Sharpe.

DAVIEWS, C. R., AYRES, J. M., DYE, C. e DEANE, L. M. 1991. "Malarial infection rate of amazonian primates increases with body weight and group size". Functional Ecology, 5:655-662.

D'ANDRADE, Roy e EGAN, M. 1974. "The colors of emotion". American Ethnologist, 1:49-63.

DENEVAN, William M. 1992. "The pristine myth: the landscape of the Americas in 1492". Annals of the Association of American Geographers, 82:369-385.

DEVANAND, D.P., MICHAELS-MARSTON, Kristin S., LIU, Xinhua, PELTON, Gregory H., PADILLA, Margarita, MARDER, Karen, BELL, Karen, STERN, Yaakov, e MAYEUX, Richard. 2000. "Olfactory 
deficits in patients with mild cognitive impairment predict Alzheimer's disease at follow-up". American Journal of Psychiatry, 157: 1399-1405.

DOBYNS, Henry. 1993. "Disease transfer at contact". Annual Review of Anthropology, 22:273-291.

DOBYNS, Henry F. 1983. Their number become thinned: native american population dynamics in Eastern North America. Knoxville: University of Tennessee Press.

DOTY, R. L., REYES, P. F., e GREGOR, T. 1987. "Presence of both odor identification and detection deficits in Alzheimer's disease". Brain Research Bulletin, 18:597-600.

ETKIN, Nina L. 1988. "Ethnopharmacology: biobehavioral approaches in the anthropological study of indigenous medicines. Annual Review of Anthropology, 17:23-42.

FIORINI, Marcelo O. 2003. "Cannibal identities: civilized predation, warfare, or eschatology". Comunicação apresentada ao encontro da American Anthropological Association. Chicago, IL.

FIRTH, Raymond. 1981. "Spiritual aroma: religion and politics". American Anthropologist, 83:582-601.

FOGELSON, Raymond. 1989. "The ethnohistory of events and nonevents". Ethnohistory, 36:133-147.

GARNHAM, P.C. e KUTTLER, K.L. 1980.

"A malaria parasite of the white-tailed deer (Odocoileus virginianus) and its relation with known species of plasmodium in other ungulates".
Proceedings of the Royal Society of London. Series B, Biological Sciences, 206:395-402.

GUERRA, Francisco. 1988. "The earliest american epidemic: the influenza of 1493". Social Science History, 12:305-325.

HAGGETT, Peter. 1994. "Geographical aspects of the emergence of infectious disease". Geografiska Annaler, Series B, Human Geography, 76:91-104.

HAHN, Robert A. e KLEINMAN, Arthur. 1983. "Belief as pathogen, belief as medicine: 'voodoo death' and the placebo phenomenon in anthropological perspective". Medical Anthropology Quarterly, 14: 3;16-19.

HARKIN, Mark. 2003. "Feeling and thinking in memory and forgetting: towards an ethnohistory of the emotions". Ethnohistory, 50: 261-284.

HEADLAND, Thomas N. 2002. "Thirty endangered languages in the Philippines". Comunicação apresentada ao encontro da American Anthropological Association, New Orleans, LA.

HERZ, Rachel S., ELIASSEN, James, BELAND, Sophia, e SOUZA, Timothy. 2004. "Neuroimaging evidence for the emotional potency of odor-evoked memory". Neuropsychologia, 42:371-378.

HUNN, Eugene. 1982. "Did the Aztecs lack potential animal domesticates?" American Ethnologist, 9: 578579.

IZARD, C. E. 1983. "Emotions in personality and culture". Ethos, 11: 305312. 
JENSEN, Cheryl. 1999. "Tupí-Guaraní". In: R. M. W. Dixon e Alexandra Y. Aikhenvald (eds.), The amazonian languages. Cambridge: Cambridge University Press. pp. 125-163.

JOHNSON, Allen, JOHNSON, Orna, e BAKSH, Michael. 1986. "The colors of emotions in Machiguenga". American Anthropologist, 88:674-681.

KRACKE, Waud H. 1981. "Kagwahiv mourning: dreams of a bereaved father". Ethos, 9:258-275. . 1988. "Kagwahive mourning II: ghosts, grief, and reminiscences". Ethos, 16:209-222.

LEAVITT, John. 1996. "Meaning and feeling in the anthropology of emotions". American Ethnologist, 23:514-539.

LIVINGSTONE, Frank B. 1958. "Anthropological implications of sickle cell gene distribution in West Africa". American Anthropologist, 60:533-562.

LUTZ, Catherine. 1986. "Emotion, thought, and estrangement: emotion as a cultural category". Cultural Anthropology, 1:287-309.

LUTZ, Catherine e WHITE, Geoffrey M. 1986. "The anthropology of emotions". Annual Review of Anthropology, 15:405-436.

LYON, Margot L. 1995. "Missing emotion: the limitations of cultural constructionism in the study of emotion". Cultural Anthropology, 10:244-263.

MARTZKE, Jeffrey S., KOPALA, Lili C., e GOOD, Kimberley P. 1997. "Olfactory dysfunction in neuropsy- chiatric disorders: review and methodological considerations". Biological Psychiatry, 42:721-732.

MCNEIL, William H. 1989. Plagues and peoples. New York: Anchor.

MOORE, Carmella C., ROMNEY, A. Kimball, HSIA, Ti-Lien, e RUSCH, Craig D. 1999. "The universality of the semantic structure of emotion terms: methods for the study of inter-and intra-cultural variability. American Anthropologist, 101:20-28.

NIMUENDAJÚ, C. 1948. "The Guajá". In: Julian H. Steward (ed.), Handbook of south american indians. Volume 3: the tropical forest tribes. $\mathrm{Bu}$ reau of American Ethnology Bulletin 143. Washington, D.C.: Smithsonian Institution Press. pp. 135-136.

OAKDALE, Suzanne. 2001. "History and forgetting in an indigenous amazonian community". Ethnohistory, 48:381-401.

POLLOCK, Donald. 2002. "Partible paternity and multiple maternity among the Kulina". In: Stephen Beckerman e Paul Valentine (eds.), Cultures of multiple fathers: the theory and practice of partible paternity in South America. Gainesville: University Press of Florida. pp. 42-61.

POLLOCK, Donald. 1996. "Personhood and illness among the Kulina". Medical Anthropology Quarterly, 10:319-341.

REDDY, William M. 1997. "Against constructionism: the historical ethnography of emotions". Current Anthropology, 38:327-351. 
ROYET, Jean P., ZALD, David, VERSACE, Rémy, COSTES, Nicolas, LAVENNE, Frank, KOENIG, Oliver, e GERVAIS, Rémi. 2002. "Emotional responses to pleasant and unpleasant olfactory, visual, and auditory stimuli: a positron emission tomography study". The Journal of Neuroscience, 20:7752-7759.

RIVAL, Laura M. 2002. Trekking through history: the Huaorani of amazonian Ecuador. New York: Columbia University Press.

RODRIGUES, Ayron D. 1984/1985. "Relações internas na família lingüística Tupí-Guaraní". Revista de Anthropologia, 27/28:33-53.

RUSTED, J. M., MARSH, R., BLEDSKI, L., e SHEPPARD, L. 1997. "Alzheimer patient's use of auditory and olfactory cues to aid verbal memory". Aging and Mental Health, 1:364372.

SAVOLAINEN, Peter, ZHANG, YaPing, LUO, Jing, LUNDEBERG, Joakim, LEITNER, Thomas. 2002. "Genetic evidence for an East Asian origin of domestic dogs". Science, 298:1610-1614.

SCHULTES, Richard Evans e RAFFAUF, Robert F. 1990. The healing forest: medicinal and toxic plants of Northwest Amazonia. Portland: Dioscorides Press.

SEEGER, Anthony. 1981. Nature and society in central Brazil: the Suyá indians of Mato Grosso. Cambridge: Harvard University Press.

SHEPARD, Glenn H. Jr. 2004. "A sensory ecology of medicinal plant therapy in two amazonian societies". American Anthropologist, 106:252-266.

SHEPARD, Glenn H. Jr. 2000. "Botanies of desire: olfaction, herbalism and sexual attraction in two amazonian societies". Comunicação apresentada ao encontro da American Anthropological Association, San Francisco, CA.

SIFFREDI, Alejandra. 2002. "Fragments of southern Tehulche religiosity and myths". In: Lawrence E. Sullivan (ed.), Native religions and cultures of Central and South America: anthropology of the sacred. New York/London. pp. 299-312.

STOLLER, Paul. 1994. "Embodying colonial memories". American Anthropologist, 96:634-648.

SCHWARTZ, Marion. 1997. A history of dogs in the early Americas. New Haven: Yale University Press.

STODDART, D. Michael. 1990. The scented ape: the biology and culture of human odour. New York/Cambridge: Cambridge University Press.

TALAMO, Barbara R., RUDEL, Ruthann, KOSIK, Kenneth S., LEE, Virginia M.Y., NEFF, Samuel, ADELMAN, Lester, e KAUER, John S. 1989. "Pathological changes in olfactory neurons in patients with Alzheimer's disease". Nature, 337:736-739.

TAYLOR, Anne-Christine. 1998. "Jivaro kinship: 'simple' and 'complex' formulas: a dravidian transformation group". In: T. R. Trautmann e F. E. Tjon Sie Fat (eds.), Transformations of kinship. Washington, D.C.: Smith- 
sonian Institution Press. pp. 187-213. . 1996. "The soul's body and its states: an amazonian perspective on being human". Journal of the Royal Anthropological Institute, 2:201-215.

1993. "Remembering to forget: identity, mourning and memory among the Jivaro". Man, 28:653-678.

TRIGGER, David S. 1999. "Hunter-gatherer peoples and nation-states". In: Richard B. Lee e Richard Daly (eds.), Cambridge encyclopedia of hunters. Cambridge: Cambridge University Press. pp. 473-479.

TUZIN, Donald. 1975. "The breath of a ghost: dreams and the fear of the dead". Ethos, 3:555-578.

VIVEIROS DE CASTRO, Eduardo. 2001. "Gut feelings about Amazonia: potential affinity and the construction of sociality". In: Neil L. Whitehead e Laura M. Rival (eds.), Beyond the visible and material: the amerindianization of society in the work of Peter Rivière. Oxford: Oxford University Press. pp. 19-43. . 1998. "Cosmological deixis and amerindian perspectivism". Journal of the Royal Anthropological Institute, 4:469-488.

. 1992. From the enemy's point of view: humanity and divinity in amazonian society. Chicago: The University of Chicago Press.

WERNER, Wilbert. 1987. "The pneumatic theory of female Warao herbalists". Social Science \& Medicine, 25:1139-1146.
WIERZBICKA, Anna. 1988. "Emotions across cultures: similarities and differences". American Anthropologist, 90:982-983. . 1986. "Human emotions: universal or culture-specific?" American Anthropologist, 90:584-594.

WIRSING, Rolf L. 1985. "The health of traditional societies and the effects of acculturation". Current Anthropology, 26:303-322.

WOOD, Corinne Shear. 1975. "New evidence for a late introduction of malaria into the New World". Current Anthropology, 16:93-104.

ZALD, David H. e PARDO, José V. 1997. "Emotion, olfaction, and the human amygdala: amygdala activation during aversive olfactory stimulation". Proceedings of the National Academy of Sciences, 94:4119-4124 


\section{Resumo}

Entre as plantas medicinais dos Guajá da Amazônia oriental incluem-se várias usadas para repelir os fantasmas dos mortos. Esse artigo discute as plantas repelentes de fantasmas aiyã, em termos de seu significado simbólico, eficácia biológica, e contexto históricoecológico. Plantas repelentes de fantasmas são identificadas por seu odor pungente, que age sobre o odor fétido causador de doenças - dos fantasmas dos mortos. A eficácia da cura pode também relacionar-se a sua interferência com o chamado "fenômeno proustiano", que se refere ao poder dos estímulos olfativos de evocar memórias do passado. Como tais, repelentes de fantasmas podem funcionar, em certo sentido, para afastar memórias e lidar com a dor da perda. Por fim, discutem-se evidências de que a predominância de repelentes de fantasmas entre as plantas medicinais dos Guajá é um efeito da baixa populacional maciça subseqüente ao contato europeu.

Palavras-chave Guajá, Plantas Medicinais, Ecologia, Olfato, Sofrimento

\section{Abstract}

The medicinal plants of the Guajá people of eastern Amazonia include a number of plants that are used to repel the ghosts of the dead. This work discusses the aiya ghost repellent plants in terms of their symbolic meaning, biological efficacy, and historical ecological context. Ghost repellent plants are identified through their pungent smell, which counteract the disease-causing foul smell of the ghosts of the dead. The efficacy of the cure may also relate to its interference with the so-called "Proustian phenomenon," which refers to the power of olfactory stimuli to evoke memories of the past. As such, ghost repellent plants may function, in a sense, to repel memory and cope with grief. Finally, evidence is discussed the predominance of ghost repellent plants among the Guajá is an artifact of massive depopulation in the wake of European contact.

Key words Guajá, Medicinal Plants, Ecology, Olfaction, Grief 